\title{
CIUDAD Y CAMBIO CLIMÁTICO: ASPECTOS GENERALES Y APLICACIÓN AL ÁREA METROPOLITANA DE MADRID
}

\author{
Felipe Fernández García ${ }^{1}$ \\ Departamento de Geografía \\ Universidad Autónoma de Madrid
}

\section{RESUMEN}

En este artículo se analizan las relaciones de la ciudad y el clima, desde una doble perspectiva: la del cambio climático y la del clima urbano. Las ciudades modifican el clima regional, contribuyen de forma notable al calentamiento global y son las áreas más vulnerables a los impactos del cambio climático: las ciudades consumen el $75 \%$ de la energía y son las responsables del $80 \%$ de las emisiones de Gases de efecto invernadero. Hemos estructurado el trabajo en tres apartados: en el primero analizaremos, a escala global, las características del clima urbano, sus impactos y las medidas propuestas para su mitigación; en los otros dos, centraremos nuestro interés en España y el área de Madrid, la zona más poblada de la península y en la que los estudios sobre clima urbano permiten plantear, a escala local, los aspectos tratados en el primer apartado.

Palabras clave: Clima urbano, Cambio Climático, Madrid.

\section{ABSTRACT}

This article analyzes the relationship between the city and the climate from two perspectives: the climate change and the urban climate. The cities transform regional climate, contribute significantly to global warming and are the most vulnerable zones to the impacts of climate change. Cities and urban areas consume $75 \%$ of the world's energy and produce up to $80 \%$ of its greenhouse gas emissions. We have divided the work into three sections: in the first one it will be discussed the characteristics of the urban climate, its impacts and the mitigation measures proposed; the other two parts will focus in Spain and Madrid, the most populated area of the peninsula and where the urban climate studies already made allow the application of the issues raised in the first paragraph on a local scale.

Key words: Urban Climate, Climate Change, Madrid.

\footnotetext{
1 felipe.fernandez@uam.es
} 


\section{Introducción}

El siglo XX ha sido el siglo del ambientalismo, de la preocupación por los aspectos ambientales y de las transformaciones que el hombre introduce en la naturaleza. Se toma conciencia del deterioro ambiental debido a la presión humana y de las consecuencias que en un futuro no muy lejano podría tener tal deterioro sobre aspectos esenciales como la producción de alimentos, el agua y los recursos naturales, en general. En 1972, en la conferencia de las Naciones Unidas sobre Medio Ambiente, celebrada en Estocolmo, se introdujo por vez primera en la agenda política internacional la dimensión ambiental como factor condicionante del modelo tradicional de crecimiento económico y del uso de los recursos naturales; en 1988 se crea el Grupo Intergubernamental de Expertos sobre el Cambio Climático o IPCC (Intergovernmental Panel for Climate Change), bajo los auspicios de la Organización Meteorológica Mundial (OMM) y el Programa de las Naciones Unidas para el Medio Ambiente (PNUMA).

El clima como factor clave de la vida en la tierra adquiere especial protagonismo y el IPCC tiene como objetivo el estudio del sistema climático, pero también, las consecuencias que podrían derivarse de un cambio en los parámetros actuales del clima. Los tres grupos de trabajo que lo forman, tienen un marcado carácter interdisciplinar y sus miembros son los encargados de recopilar, depurar y publicar los principales avances científicos en tres aspectos fundamentales como son: primero, el estudio del sistema climático, su variabilidad y tendencias; segundo, los impactos del clima sobre la sociedad y los ecosistemas y, tercero, las medida de adaptación y mitigación que se deberían tomar para minimizar los efectos negativos.

Sus informes se han convertido en el referente de la política ambiental actual, con implicaciones en todos los sectores económicos, sociales y ambientales del mundo actual (http://www.ipcc.ch).

Los cuatro informes publicados hasta la fecha (1990, 1995, 2001 y 2007) han demostrado que el clima actual se encuentra en un proceso de cambio en relación al patrón normal de los últimos 10.000 años; que en ese cambio influyen de manera muy notable las transformaciones del hombre sobre la superficie terrestre y la atmósfera y que el cambio climático es un fenómeno mundial con repercusiones muy negativas sobre la sociedad y los ecosistemas.

El siglo XX ha sido, también, el siglo de la urbanización: la población urbana ha pasado de un $15 \%$ en 1890 a más del $50 \%$ en el año 2000 y las proyecciones futuras indican que este fenómeno continuará a lo largo de este siglo, de tal modo que en 2050 el $70 \%$ de la población vivirá en ciudades de más de 10 millones de habitantes, por lo que las megaciudades serán el fenómeno urbano del siglo XXI (UN-HABITAT, 2008).

La ciudad constituye la forma más radical de transformación del paisaje natural y su aparición da lugar a un espacio eminentemente antropizado en el que la actuación del hombre se manifiesta en una doble vertiente: por un lado las modificaciones que el hombre introduce directa y conscientemente y que tienen su mejor manifestación en el plano y morfología urbanos; de otro las que indirectamente se derivan de este mismo espacio construido y cuyas manifestaciones más significativas son la contaminación de la atmósfera urbana y un aumento térmico en relación a las zonas próximas, conocido como isla de calor.

La magnitud del proceso de urbanización ha convertido a las ciudades en auténticos laboratorios de experimentación de los efectos derivados de la acción del hombre sobre el medio natural, de sus impactos sobre la sociedad y de las medidas de adaptación y mitigación necesarias para combatirlos. Pensemos que, aunque el área ocupada por las ciudades, apenas representa el $2 \%$ de la superficie del planeta, su impacto, la denominada huella ecológica, se extiende mucho más allá de sus límites, convirtiéndose las ciudades en 
auténticos «puntos calientes» a partir de los cuales se originan alteraciones ambientales que alcanzan la escala de lo global: las zonas urbanas consumen más del 75\% de los recursos naturales y de ellas proceden más del $80 \%$ de las emisiones de gases a la atmósfera.

La climatología urbana se enfrenta al gran reto que supone caracterizar lo que algunos autores han definido como el clima urbano ideal, entendiendo como tal aquel que permite a los habitantes de las ciudades gozar de un aire limpio y una ausencia de estrés térmico y, al mismo tiempo, minimizar los impactos de la ciudad sobre el calentamiento global (Souch and Grimmond, 2006).

Es desde esta óptica que abordaremos el estudio de las relaciones entre la ciudad y el cambio climático y por ello hemos estructurado el trabajo en tres apartados: en el primero analizaremos, a escala global, las características del clima urbano, sus impactos y las medidas propuestas para su mitigación; en los otros dos, centraremos nuestro interés en España, tomando como ejemplo el área de Madrid, la zona más poblada de la península y en las que los estudios sobre clima urbano permiten plantear a escala local los aspectos tratados en el primer apartado.

\section{Cambio climático y clima urbano}

1. El cambio climático: El cuarto informe del IPCC (IPCC, 2007a) concluye que el calentamiento global es inequívoco y que este calentamiento afecta a otros aspectos del clima como el calentamiento de los océanos, los modelos de circulación, la frecuencia de eventos extremos en las temperaturas, las precipitaciones y el viento. El informe indica, también, que este calentamiento se mantendrá a lo largo del siglo XXI, entre $1.8^{\circ} \mathrm{C} \mathrm{y} 4^{\circ} \mathrm{C}$ en relación al periodo 1961-1990 y un aumento medio del nivel del mar entre $18 \mathrm{~cm}$ y $59 \mathrm{~cm}$.

Uno de los aspectos más interesantes del calentamiento actual del clima es el papel de la acción del hombre sobre el mismo. Dos son las actuaciones más importantes que han contribuido al calentamiento: la primera, se relaciona con los cambios de uso del suelo, que han modificado los balances de radiación entre la superficie y la atmósfera; la segunda, las emisiones derivadas de la quema de combustibles fósiles, que han aumentado de las concentraciones de los gases de efecto invernadero (GEI). Frenar el calentamiento es el gran reto al que se enfrenta la sociedad y las medidas más efectivas son aquellas que tiende a reducir el consumo energético y la sustitución de los combustibles fósiles por otros menos contaminantes.

2. El clima urbano. Las áreas urbanas reproducen, a escala local, los cambios e impactos observados a escala global y el clima urbano se define como un clima regional modificado. La «atmósfera urbana» presenta rasgos claramente diferenciados del resto, especialmente en las temperaturas y la composición del air: las primeras, se modifican debido a todos los procesos energéticos que se producen en el interior de la ciudad y que comprende los flujos de radiación, asociados al calor latente y sensible, así como los flujos de calor almacenado en el suelo, los edificios y el generado por el hombre y sus actividades; por otro lado, la composición del aire se modifica debido a las emisiones de contaminantes procedentes de los focos de calor domésticos, industriales y al tráfico rodado.

2.1. La isla de calor. El asfalto, los edificios y el trazado de la red viaria modifican los balances de radiación entre el suelo y el aire, reducen la evaporación, aumentan la escorrentía superficial y disminuyen la velocidad del viento a la vez que aumenta la turbulencia. Todo ello se traduce en un clima urbano característico, cuyo rasgo más destacable es el aumento de las temperaturas en la ciudad en relación a las áreas vecinas más frías. 
La isla de calor isla de calor urbana o UHI (Urban Heat Island) es el concepto que mejor define el clima urbano y en cualquier ciudad se pueden distinguir dos tipos: la primera, denominada isla de calor atmosférica, representa las diferencias en la temperatura del aire entre las zonas urbanas y las rurales; la segunda, denominada isla de calor superficial, indica la diferencia entre la temperatura registrada en los materiales urbanos (pavimento, aceras, tejados de los edificios etc.) y el aire situado encima de ellos (Voogt, J.A. and T.R. Oke, 2003). Entre ambas se pueden observar diferencias en los mecanismos de formación, las técnicas empleadas para su identificación y las medidas de mitigación (Cuadro 1).

\section{Cuadro 1 \\ CARACTERÍSTICAS DE LA ISLA DE CALOR ATMOSFÉRICA Y LA ISLA DE CALOR SUPERFICIAL}

\begin{tabular}{|l|l|l|}
\hline & \multicolumn{1}{|c|}{ Isla de calor atmosférica } & \multicolumn{1}{c|}{ Isla de calor superficial } \\
\hline Ritmo temporal & $\begin{array}{l}\text { - Débil o inexistente durante el } \\
\text { día; } \\
\text { Máxima en invierno y durante } \\
\text { la noche }\end{array}$ & $\begin{array}{l}\text { - Se mantiene durante el día y la } \\
\text { noche } \\
\text { Máxima intensidad durante el } \\
\text { día y en verano }\end{array}$ \\
\hline $\begin{array}{l}\text { Método de } \\
\text { identificación }\end{array}$ & $\bullet$ Teledetección & $\begin{array}{l}\text { - Estaciones meteorológicas fijas } \\
\text { Transectos }\end{array}$ \\
\hline Representación & $\begin{array}{l}\text { - Mapas de isotermas } \\
\text { - Gráficos }\end{array}$ & - Imágenes térmicas \\
\hline Mitigación & $\begin{array}{l}\text { - Morfología y estructura urbana } \\
\text { - Aumento zonas verdes }\end{array}$ & - Modificación tipo de materiales \\
\hline
\end{tabular}

(EPA, 2008, modificado)

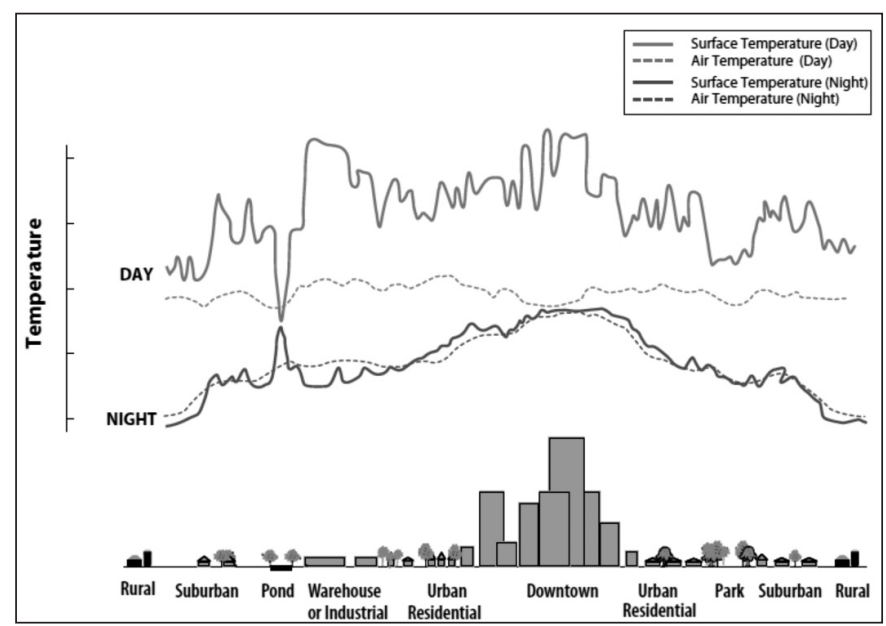

Figura 1: Evolución diaria de las temperaturas del aire y del suelo. Fuente: EPA, (2008). 
Tanto una como otra están muy influenciadas por los usos del suelo y las diferentes tipologías urbanas presentes en la ciudad, lo que determina que durante el día la temperatura superficial presente importantes oscilaciones provocadas, tanto por los contrastes entre zonas expuestas al sol y las sombras creadas por los edificios, como por la gran variedad de materiales presentes en el escenario urbano; durante la noche ambas curvas siguen un ritmo similar con los picos más altos en las zonas de mayor densidad edificatoria (fig. 1).

2.2. Impactos de la ciudad. El aumento térmico y empeoramiento de la calidad del aire son los dos rasgos distintivos del clima urbano y los principales factores de riesgo, tanto por sus efectos directos sobre la mortalidad y morbilidad, como por el gran número de personas potencialmente expuestas.

La influencia de las altas temperaturas sobre la mortalidad es un hecho demostrado por numerosos estudios (García, J.C. y Alberdi, J.C., 2004; Fischer et al., 2004) y en todos ellos se observa la existencia de umbral crítico, a partir del cual la mortalidad aumenta (Fig. 2).

La isla de calor, además, influye de forma directa en el aumento del consumo de electricidad, especialmente en verano (figura 3): en los Ángeles, Akbari et al. (2001) calcularon que cada grado de incremento térmico por encima de $20^{\circ} \mathrm{C}$, determina un aumento de 500 megavatios en la demanda de consumo eléctrico para el aire acondicionado; así mismo, que las concentraciones de ozono troposférico se incrementan en un $5 \%$ por cada grado de calentamiento por encima de los $22^{\circ} \mathrm{C}$.

La contaminación del aire es otro de los rasgos característicos de la ciudad y un importante factor de riesgo para la población. La OMS (2009), estima que la contaminación del aire es responsable de 1,4\% de las muertes mundiales (fig. 4) y la población potencialmente expuesta a niveles peligrosos de contaminación por $\mathrm{NO}_{2}$, partículas en suspensión y ozono troposférico supera el $30 \%$ de la población en las ciudades europeas.

Además, las ciudades contribuyen de forma clara al calentamiento global, ya que de ellas proceden más del $80 \%$ de los GEI vertidos a la atmósfera.

La isla de calor, sin embargo, es un fenómeno de carácter local, con escasa incidencia en el calentamiento global, tal y como se demuestra en numerosos trabajos científicos (Parker, 2004; Peterson, 2003; CLIVAR, 2009).

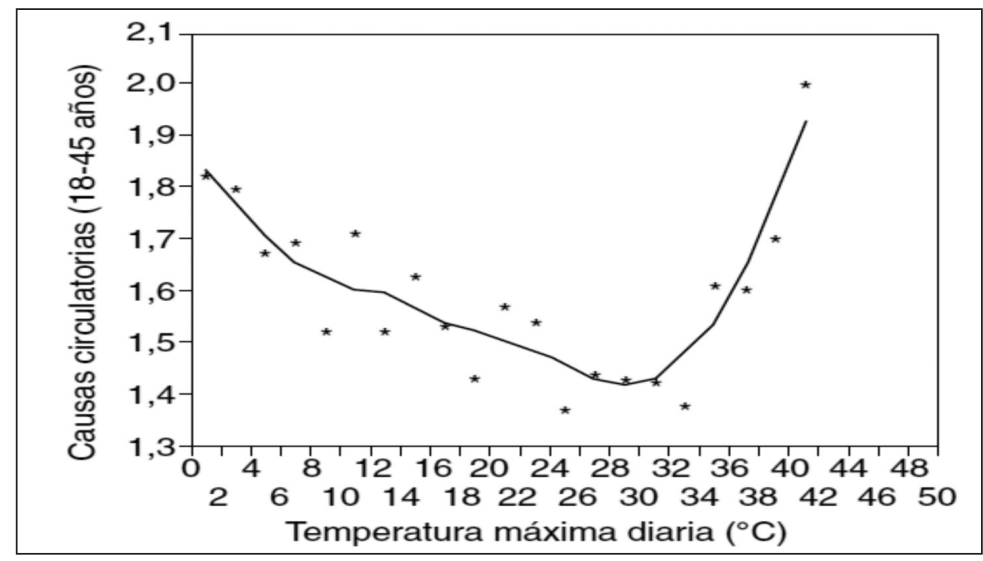

FIgURA 2. Relación entre mortalidad y temperatura máxima diaria.

Fuente: Cristina Linares / Julio Díaz. 


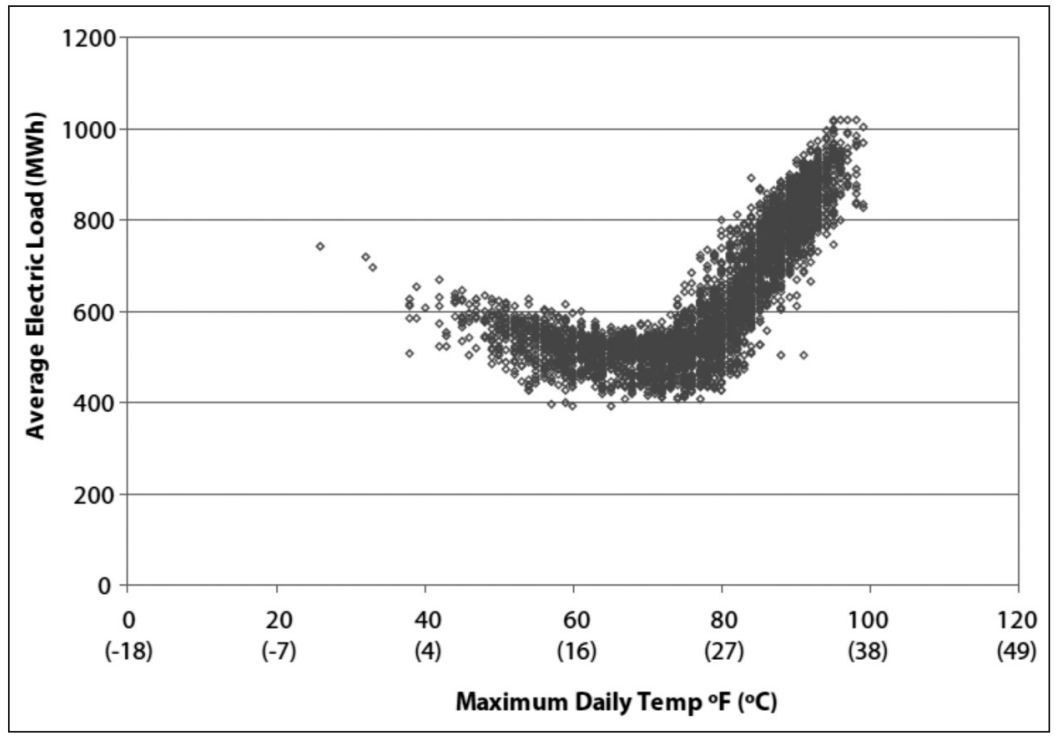

FIgURA 3. Relación entre aumento térmico y consumo de electricidad en Nueva Orleans. Fuente: (EPA, 2008).

\section{Deaths from urban air pollution}

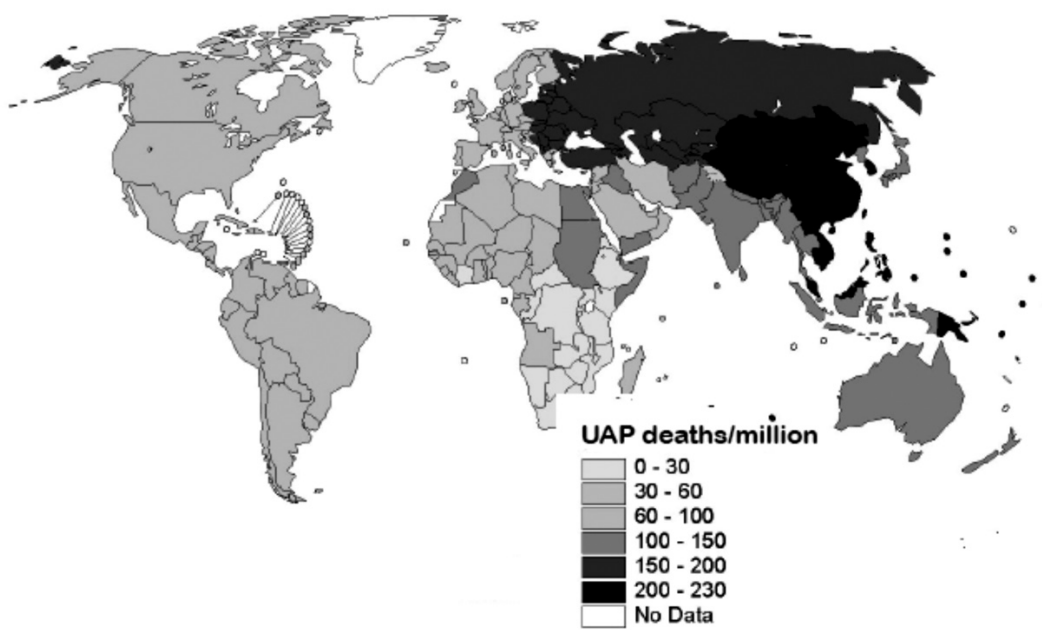

FIGURA 4: Mortalidad por contaminación urbana.

Fuente: WHO, 2006. 


\section{Impactos del cambio climático en las ciudades}

Las ciudades son especialmente vulnerables a los efectos del cambio climático, especialmente al aumento térmico, al del nivel del mar y a la disminución de las disponibilidades hídricas. A pesar de ello, los estudios sobre los impactos potenciales del cambio climático a escala urbana son muy generales y limitados a un número muy reducido de ciudades, aunque en los últimos años están adquiriendo mayor importancia.

Un reciente informe, encargado por la OCDE (Hunt \& Watkiss, 2007), señala que la vulnerabilidad a escala urbana depende del tamaño, de la localización y de la economía de la ciudad y que los impactos más relevantes serán los relativos al consumo energético, a la salud de la población y a la escasez de recursos hídricos.

- La demanda energética. Las ciudades son las principales consumidoras de energía y las principales emisoras de gases contaminantes a la atmósfera. El transporte, la calefacción, la iluminación y los aparatos de aire acondicionado consumen más del $50 \%$ de la energía en ciudades como Nueva York, Londres y Tokio (Un-Habitat, 2008), por lo que la demanda energética en las ciudades está muy ligada a las condiciones climáticas. A medio y largo plazo, las previsiones apuntan a un aumento del consumo de electricidad para refrigeración en verano, al tiempo que disminuirá la demanda de calefacción. La magnitud de estos efectos dependerá de la zona climática donde se ubique la ciudad, de las condiciones socio-económicas y de otros factores difícilmente cuantificables, pero existe un amplio consenso en considerar que la demanda de energía es la categoría más afectada por el cambio climático en las ciudades.

Informes realizados por la Agencia Europea de Medio Ambiente (2007), estiman que en los países del sur de Europa se prevén fuertes aumentos en la demanda eléctrica en verano, al tiempo que disminuirá el consumo para calefacción, especialmente en los países más fríos del norte. A título de ejemplo, en Atenas la demanda de electricidad en 2080 aumentará en un 30\% durante el mes de julio, respecto a la actual (Giannakopoulous, 2006), mientras que en Londres, el aumento estimado es del $10 \%$ en 2050 y en torno al $20 \%$ en 2080 (LCCP, 2002); en Boston, los días en los que se necesitará aire acondicionado aumentarán un $24 \%$ y el consumo eléctrico, oscilará entre un $25 \%$ y un $40 \%$ (Kirshen et al., 2004).

- La salud y el bienestar de las personas es otro de los impactos derivados del cambio climático, que en las ciudades alcanza especial importancia por el elevado número de personas que en ellas habitan y por el envejecimiento de la población, especialmente en los países desarrollados. La influencia puede ser directa por los efectos fisiológicos del calor y el frío, o indirecta, a través del aumento de vectores patógenos que pueden desplazarse a latitudes más altas como consecuencia del calentamiento.

El aumento de la mortalidad y morbilidad asociada al calor es un hecho demostrado y el mejor ejemplo lo encontramos en la ola de calor del verano de 2003, que provocó más de 35000 muertes en Europa. Es preciso tener en cuenta, sin embargo, que aunque es probable que haya aumentos en la mortalidad relacionada con el calor, estos podrían ser compensados por la disminución de la mortalidad relacionada con el frío. Como en el caso anterior la cuantificación presenta grandes incertidumbres por la capacidad de adaptación de la población y por la eficiencia de medidas de prevención como los sistemas de alerta, ya implantados en numerosos países.

- Los recursos hídricos. La escasez de agua es otro de los impactos relacionados con el cambio climático, cuyos efectos serán importantes en las áreas urbanas. Muchos 
expertos aseguran que la falta de agua potable, además de constituir uno de los mayores problemas que aquejan actualmente a la humanidad, va a ser uno de los principales factores limitantes para la expansión urbana durante el siglo XXI. El aumento térmico provoca una mayor evaporación y, consiguientemente una disminución de las disponibilidades hídricas, incluso en el caso de que las precipitaciones no varíen.

En relación con la elevación del nivel mar y el aumento de episodios de precipitaciones intensas, las ciudades más vulnerables son las próximas a las zonas de costa y cauces fluviales: según datos del IPCC, la población expuesta a estos impactos se cifra en más de 1000 millones, aquellas que viven a menos de $100 \mathrm{~km}$ de las costas y en zonas de menos de 100 metros de altitud. Así mismo, indica que el aumento de $21 \mathrm{~cm}$ en el nivel del mar, previsto para 2100, dará lugar a la desaparición del $17.5 \%$ de la superficie de Bangladesh y supondrá el desplazamiento de entre 8 y 10 millones de personas en países como Egipto o Vietnam.

4. Estrategias de mitigación. Muchos gobiernos y entidades municipales están desarrollando leyes o incorporando normativas dirigidas a mejorar la calidad ambiental en el entorno propiamente urbano y disminuir las emisiones de contaminantes como medida de mitigación del cambio climático global. Las medidas tienen como objetivo disminuir las emisiones contaminantes con edificios más eficientes energéticamente, una movilidad urbana tendente a reducir el uso del vehículo privado y un urbanismo más acorde con las condiciones climáticas del entorno.

En todo este proceso, la disminución de la isla de calor urbana es uno de los objetivos prioritarios, especialmente en las ciudades situadas en climas cálidos.

Tres son las acciones propuestas (Akbari, H., 2009, EPA, 2008): aumento de las zonas verdes, transformación de las cubiertas de los edificios (green roofl cool roof) y de los materiales y el color del pavimento.

- Los árboles y la vegetación contribuyen al enfriamiento mediante la sombra y la evaporación. La sombra reduce la radiación recibida por la superficie evitando la emisión de calor hacia el aire y los edificios circundantes; por su parte, el calor utilizado para la evapotranspiración, también, contribuye al enfriamiento. La combinación de ambos aspectos contribuye de forma notable a la atenuación de los picos térmicos y a una notable reducción de las temperaturas: en una zona arbolada puede alcanzar una temperatura $5^{\circ} \mathrm{C}$ más baja que una zona sin árboles; sobre una superficie irrigada entre $2^{\circ} \mathrm{C}$ y $3^{\circ} \mathrm{C}$ y sobre césped entre $1^{\circ} \mathrm{C}$ ó $2^{\circ} \mathrm{C}$. De forma indirecta, este descenso térmico contribuye a una menor demanda de electricidad para el aire acondicionado de las viviendas y oficinas, que puede oscilar entre el $7 \%$ y el 47\%; también, a la disminución de la contaminación y las emisiones de gases a la atmósfera y la captura directa del $\mathrm{CO}_{2}$, estimándose en 784,000 toneladas año la disminución de emisiones debida a la superficie arbolada de las ciudades en USA y en 24 millones de toneladas, la captura de $\mathrm{CO}_{2}$ (Nowak et al., 2006).

El aumento de la superficie vegetal, podría tener, también, consecuencias negativas, entre las que podemos destacar tres: la primera, el incremento de emisiones de elementos volátiles (VOC), precursores de la formación del ozono troposférico; la segunda, una mayor demanda de agua para irrigación y la tercera, la mayor humedad relativa del aire, que es un factor adicional de disconfort en las ciudades tropicales húmedas. 
- Los tejados verdes (Green roof) consisten en sustituir las cubiertas tradicionales de los edificios por una cubierta vegetal que disminuye la trasmisión térmica, manteniendo una temperatura fresca dentro del edificio, a la vez que enfría el aire exterior, del mismo modo que lo hace la vegetación en las zonas urbanas arboladas. Esta es una tecnología emergente que está adquiriendo bastante importancia en numerosas ciudades europeas y americanas (Liu, K. y B. Baskaran, 2003).

- Los tejados fríos (Cool roof) es otra de las técnicas utilizadas, consistente en la sustitución de los materiales típicos de las cubiertas de los edificios por otros de colores claros y con alto albedo, a fin de reducir la absorción de la radiación solar. La aplicación de esta técnica a otras superficies, como el asfalto y las aceras, contribuirá a una reducción notable en el ahorro energético y la consecuente disminución de emisiones contaminantes.

Experimentos realizados en Estados Unidos (Rosenfeld et al. 1998) apuntan que a nivel nacional se podría producir un ahorro de unos $10 \mathrm{TWh} / \mathrm{año}$, lo que representa el $3,0 \%$ del consumo en refrigeración por aire acondicionado en los edificios residenciales y comerciales.

\section{Ciudad y cambio climático en España}

1. El cambio climático en España. España es muy vulnerable al cambio climático como consecuencia de su situación geográfica y sus características socioeconómicas. La temperatura del aire en la España peninsular ha mostrado indudables signos de calentamiento a lo largo del periodo instrumental 1850-2006, destacando un calentamiento sin precedentes, que viene produciéndose desde 1973 hasta el presente, con un aumento promedio de la temperatura media diaria de $0,48^{\circ} \mathrm{C}$; además, las proyecciones de los diferentes modelos de simulación, apuntan hacia un incremento progresivo de la temperatura superficial a lo largo del siglo XXI, que será mayor en verano y en las regiones del interior (Brunet et al., 2007; Martín Vide et al., 2005, MMA, 2007).

La evolución futura de las precipitaciones presentan grandes incertidumbres, aunque es bastante probable que los problemas actuales se mantengan o empeoren, debido a la mayor evaporación, el aumento de la irregularidad pluviométrica y la mayor demanda para regadío y usos urbanos (CLIVAR, 2009).

En relación al nivel del mar, los datos disponibles muestran un aumento en todas las costas peninsulares, durante la segunda mitad del siglo XX y se estima que en 2050 se produzca un retroceso de hasta 15 m en Canarias, Huelva y Cádiz y de 70 metros en puntos de la Costa Brava, Islas Baleares y sur de Canarias (MMARM, 2007, CLIVAR, 2009).

2. Urbanización y cambios en la ocupación y usos del suelo: En España más del $76,3 \%$ de la población vive en municipios que superan los diez mil habitantes y el 50,6\% en municipios que superan los cincuenta mil. En el último tercio del siglo pasado se ha producido un proceso urbanizador sin precedentes, de tal manera que entre 1987 y 2000, la superficie de suelo artificial aumentó en un 29,5\%. En Cataluña, Valencia, Murcia y Andalucía el porcentaje de superficie artificial en el primer kilómetro de costa es superior al $20 \%$ y las comunidades donde se produjo el mayor aumento de zonas urbanas, con tasas superiores al 30\%, han sido Madrid, Baleares y Canarias (Guaitia et al., 2008, CONAMA, 2009, OSE, 2010).

El impacto del cambio climático en las zonas urbanas españolas presenta, por tanto, características similares a las que hemos expuesto anteriormente aunque se puede establecer, a 
grandes rasgos, una diferenciación entre las ciudades del interior y las costeras. En las primeras, los principales impactos son los relacionados con el calentamiento global y la escasez hídrica, dependiendo su magnitud del tamaño e intensidad de la isla de calor; las costeras, por su parte, son las más vulnerables al aumento del nivel del mar, y el aumento térmico podría influir de forma importante en el turismo de mar y playa, afectando más negativamente a los centros turísticos de las costas mediterráneas y andaluzas, mientras que los situados en la cornisa cantábrica y las costas gallegas se verían favorecidas por el aumento térmico.

3. Medidas de mitigación: Para hacer frente a esta situación, el Ministerio de Medio Ambiente, a través de la «Oficina Española del Cambio Climático» ha elaborado el «Plan Nacional de Adaptación», con un doble objetivo: el primero favorecer aquellas investigaciones dirigidas al conocimiento de las consecuencias que este cambio tendrá en diferentes áreas y sobre diferentes sectores de nuestra sociedad; el segundo, generar las herramientas necesarias para mitigar los impactos. El plan se articula en torno a cuatro grandes acciones: las dos primeras dirigidas a evaluar la vulnerabilidad actual y los riesgos futuros; las dos siguientes en la formulación de estrategias y la aplicación de procesos de adaptación con objeto de fortalecer la capacidad de adaptación y reducir los impactos.

En el caso concreto del urbanismo y la construcción, se señala que las estrategias de ordenación del territorio y los planes urbanísticos deben prestar una atención especial a la información climática, tanto para la elaboración de la normativa técnica sobre edificación, como para una adecuada realización de los proyectos que considere las características climáticas de la zona, donde se vayan a ubicar los edificios. Se trata, en definitiva, de elaborar normas que conduzcan al aprovechamiento óptimo de las condiciones climáticas en los sectores urbanísticos y de la construcción.

$\mathrm{Al}$ amparo de esta legislación han surgido las Agendas 21, la Estrategia Local de Cambio Climático, de la Red Española de Ciudades por el Clima, la Estrategia Española de Sostenibilidad Urbana y Local, además de los informes y estudios sobre temas ambientales y de sostenibilidad realizados por diversos organismos dependientes del Ministerio de Medio Ambiente (http://www.mma.es/portal/secciones/).

Una visión global del impacto de las ciudades españolas en el cambio global aparece en el reciente informe publicado por la fundación CONAMA y el Observatorio de la Sostenibilidad en España (2009). En él se proponen una serie de estrategias tendentes a reducir las cargas ambientales urbanas en el horizonte 2020-2050, centradas en ocho aspectos fundamentales:

- la edificación y la ocupación de suelo,

- el consumo energético y las emisiones de gases de efecto invernadero,

- la movilidad urbana,

- la calidad del aire en las ciudades,

- el consumo de materiales y la generación de residuos urbanos,

- el ciclo urbano del agua,

- la biodiversidad y

- la huella ecológica urbana)

El análisis y las estrategias para minimizar el impacto de cada uno de ellos, en el horizonte temporal 2020-2050, se plantean en tres escenarios de evolución futura: el escenario tendencial (ESCT), basado en el mantenimiento de las lógicas vigentes; el escenario esperable (ESCE), como resultado de los cambios incorporados y en vías de introducción y el escenario deseable (ESCD), con cambios sustanciales en el actual modelo económico y social. 


\section{Ciudad y cambio climático en el área de Madrid}

\section{El área de estudio}

El área metropolitana de Madrid es una zona muy transformada por la acción del hombre, con una gran concentración de la población en torno a Madrid, la mayor ciudad de España: más de 5000.000 de personas viven en un radio inferior a $50 \mathrm{~km}$ en torno a la capital, de los que un millón, en torno al $20 \%$ de la población total, constituyen grupos de riesgo, menores de 5 años y mayores de 65. (Cuadro 2),

Cuadro 2

POBLACIÓN EN MADRID Y ÁREA METROPOLITANA

\begin{tabular}{|l|r|r|r|r|r|}
\hline & Población Total & Menores de 5 & \% & más de 65 & \multicolumn{1}{c|}{} \\
\hline Comunidad de Madrid & 6081689 & 340674 & 5.6 & 866031 & 14.2 \\
\hline Madrid & $\mathbf{3 1 3 2 4 6 3}$ & $\mathbf{1 5 1 0 7 7}$ & $\mathbf{4 . 8}$ & $\mathbf{5 8 7 6 8 2}$ & $\mathbf{1 8 . 8}$ \\
\hline AME & 538447 & 32378 & 6.0 & 45349 & 8.4 \\
\hline AMN & 255969 & 15587 & 6.1 & 22860 & 8.9 \\
\hline AMO & 208061 & 17529 & 8.4 & 15556 & 7.5 \\
\hline AMS & 1046465 & 59653 & 5.7 & 102778 & 9.8 \\
\hline Total Madrid y AM & $\mathbf{5 1 8 1 4 0 5}$ & $\mathbf{2 7 6 2 2 4}$ & $\mathbf{5 . 3}$ & $\mathbf{7 7 4 2 2 5}$ & $\mathbf{1 4 . 9}$ \\
\hline
\end{tabular}

(Elaboración propia a partir de los datos del Instituto de Estadística de la Comunidad de Madrid, año 2007).

Es la zona donde el proceso de artificialización ha alcanzado los mayores niveles registrados en todo el territorio peninsular (Fig. 5), con un claro predominio de los usos urbanos. De la vegetación natural sólo se conservan masas forestales importantes al norte y noroeste (Monte del Pardo, Valdelatas y la Casa de Campo), mientras que en el sur y suroeste predominan las grandes extensiones dedicadas al cultivo de secano, con algunas manchas residuales de vegetación de ribera en los sotos de Arganda y Rivas y pequeñas comunidades de coníferas (Fig. 6).

El hecho urbano es el principal determinante de las modificaciones ambientales y, entre ellas destaca la formación de un clima urbano claramente diferenciado del clima regional, por lo que es una zona de gran interés desde la óptica climática. Los estudios sobre el clima urbano de Madrid se iniciaron en 1984 (López Gómez y Fernández García, 1984) y desde entonces, son numerosas las publicaciones que se han realizado sobre la isla de calor, el confort, y la contaminación atmosférica (López Gómez et al., 1993, Fernández García et al., 2003, Fernández García, 2001-2002 y 2005); otros, han demostrado la influencia de las olas de calor sobre la mortalidad en Madrid (García, J.C. y Alberdi, 2004) y la influencia de la isla de calor durante las olas de calor (Fernández García y Rasilla Álvarez, 2008). En la actualidad Madrid ha sido seleccionada para implementar los métodos que se aplicarán en otras ciudades europeas para prevenir y reducir los impactos de las olas de calor en el marco del calentamiento global. Con tal finalidad se desarrolló en el verano de 2008 el proyecto DESIREX (Sobrino et al., 2009), financiado por la Agencia Europea. 


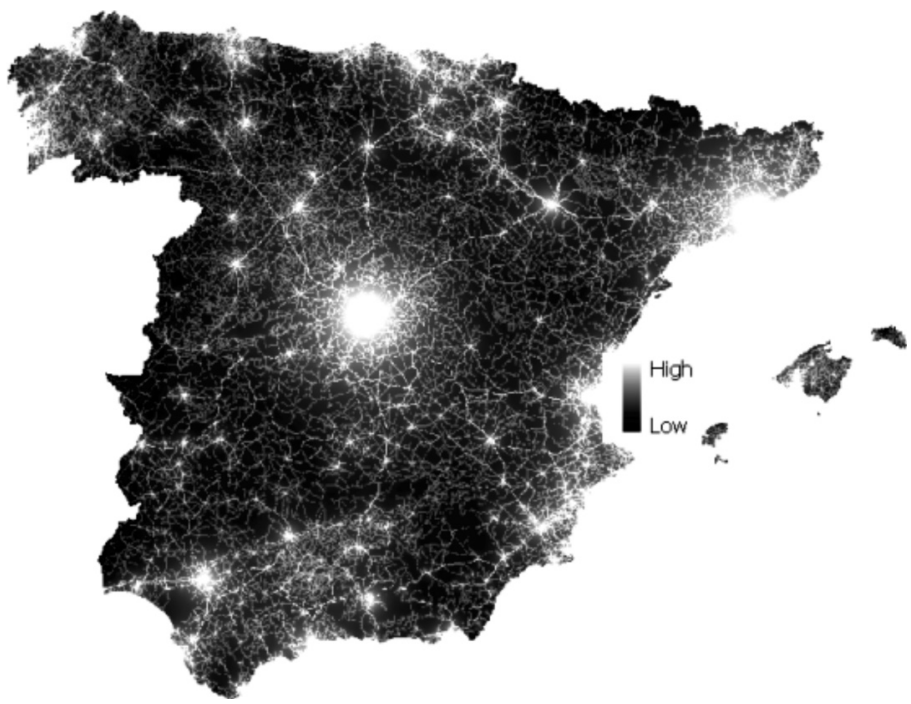

FIGURA 5: Índice de transformación del territorio peninsular. Fuente: MMARM.

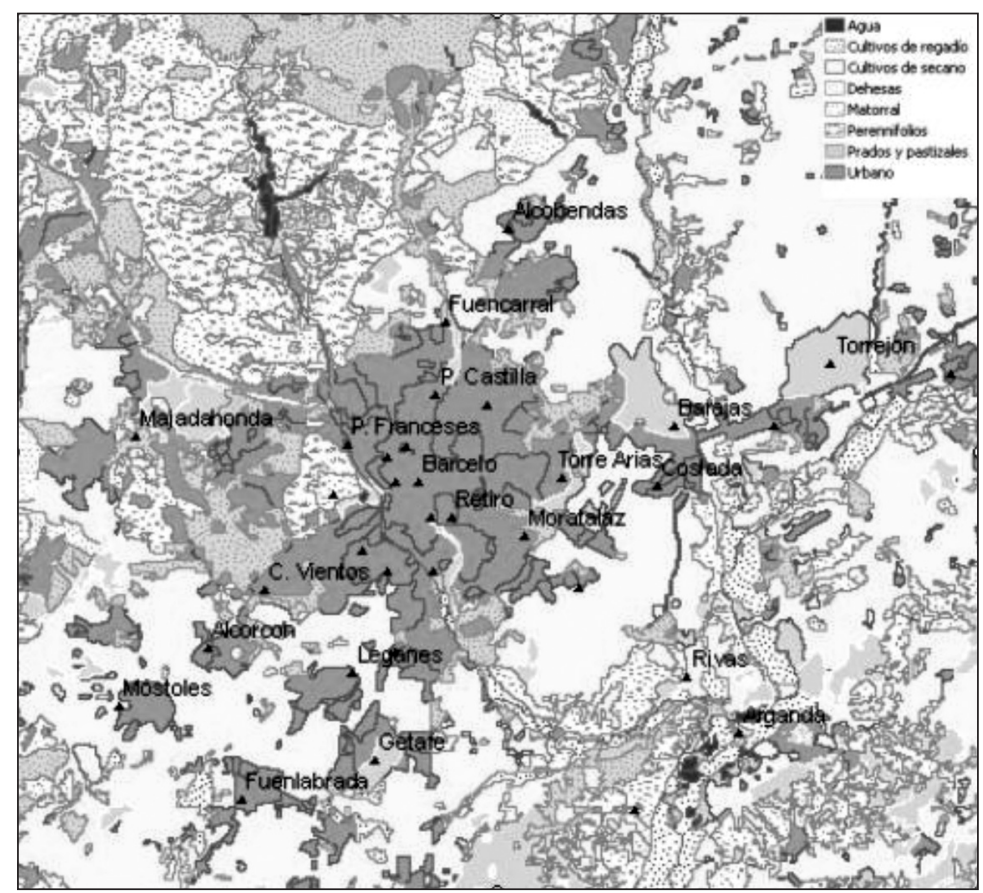

Figura 6. Distribución de usos del suelo en el área metropolitana de Madrid. Fuente: Felipe Fernández. Elaboración propia. 


\section{Características de la isla de calor en Madrid}

El clima regional está determinado por su situación en el interior de la Península Ibérica y presenta los rasgos típicos de una zona mediterránea continental, como son las escasas precipitaciones, una elevada insolación y fuertes amplitudes térmicas.

La ciudad modifica el clima regional, apareciendo las áreas urbanizadas como islas de calor, cuya intensidad y extensión varían en función de las situaciones meteorológicas, la densidad de edificaciones y la existencia de espacios verdes y zonas arboladas, tal y como se muestra en el siguiente cuadro (3).

\section{Cuadro 3}

\section{COEFICIENTES DE CORRELACIÓN DE PEARSON ENTRE LOS VALORES METEOROLÓGICOS OBSERVADOS Y LOS USOS DEL SUELO EN UNA CUADRÍCULA DE $1 \mathrm{KM}^{2}$.}

\begin{tabular}{|l|l|}
\hline Usos & T mínimas medias \\
\hline Vegetación & -0.23 \\
\hline Cultivos de secano & -0.25 \\
\hline Urbanización & 0.85 \\
\hline
\end{tabular}

Fuente: Fernández García, 2005.

El mapa térmico, elaborado a partir de las correlaciones existentes entre las temperaturas medidas en las diversas estaciones meteorológicas y los usos del suelo (Fig 7), dibuja un auténtico archipiélago de islas de calor, destacando, por su extensión e intensidad, el área ocupada por la capital y una serie de islas de menor intensidad en los núcleos suburbanos próximos.

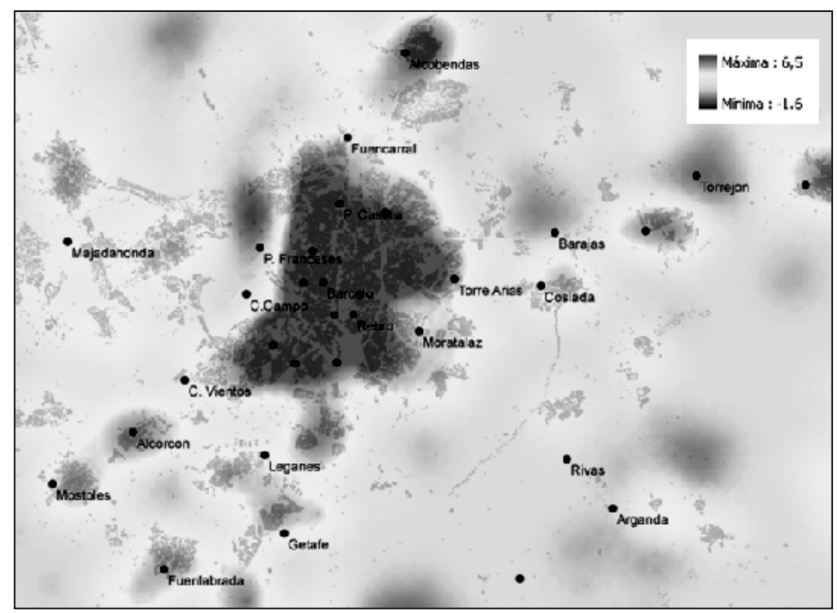

FIgURA 7. Temperaturas mínimas medias de enero en el área metropolitana madrileña. Fuente: Felipe Fernández. Elaboración propia. 
La isla de calor depende, además, de otros factores como la radiación, el viento y la nubosidad, de tal manera que es más frecuente durante la noche y disminuye, o incluso desaparece durante el día. El ritmo diario medio es el que aparece en los dos gráficos siguientes (Fig. 8). En ellos se han representado, mediante líneas, las temperaturas horarias medias de enero y julio en una estación urbana $(\mathrm{Tu})$ y otra situada en una zona con muy escasa edificación (Tnu) y, mediante barras, las diferencias térmicas entre ambas, que nos indica la intensidad de la isla de calor.

La isla de calor comienza a formarse poco después de la puesta del sol y alcanza su máxima intensidad antes del amanecer; a partir de ese momento las diferencias térmicas entre ambas zonas se reducen y con ello la intensidad de la isla de calor, que puede llegar a ser negativa. Es interesante observar, también, que la intensidad de la isla de calor es en julio entre $1^{\circ} \mathrm{C}$ y $2^{\circ} \mathrm{C}$ más elevada que en enero, señal inequívova de que el efecto urbano se agudiza durante los episodios cálidos, como tendremos ocasión de ver más adelante.
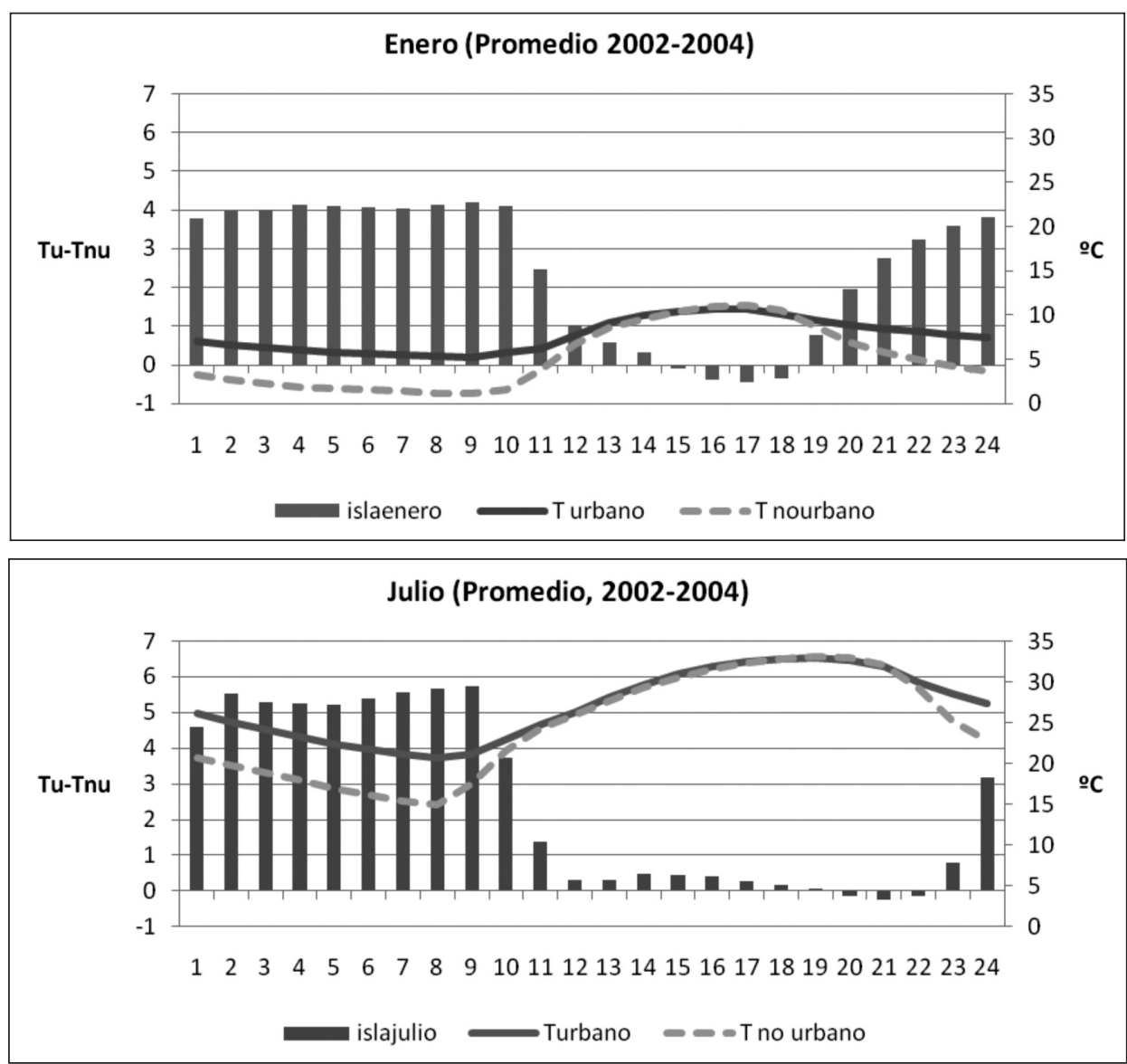

Figura 8: Evolución horaria de las temperaturas e intensidad de la isla de calor en Madrid. Fuente: Felipe Fernández. Elaboración propia con datos de de la red municipal de Madrid. En el eje horizontal, hora local. 
Las propiedades físicas de los materiales urbanos determina que durante el día la ciudad actúe como un acumulador de calor, que es devuelto a la atmósfera durante la noche calentando el aire urbano. Las zonas no urbanas se calientan lentamente, pero se enfrían rápidamente, lo que explica, a grandes rasgos, el ritmo diario que acabamos de exponer. En detalle el proceso es más complejo por la gran diversidad de materiales que conforman la ciudad, además de las sombras proyectadas por los edificios; todo ello determina que la temperatura del suelo sea muy irregular durante el día y la diferencia con la temperatura del aire sea bastante más acusada que durante la noche, tal y como se muestra en el gráfico siguiente (Fig. 9). La isla de calor superficial y la isla de calor atmosférica, siguen, por tanto, un esquema similar al analizado en otras ciudades (véase Fig. 1).

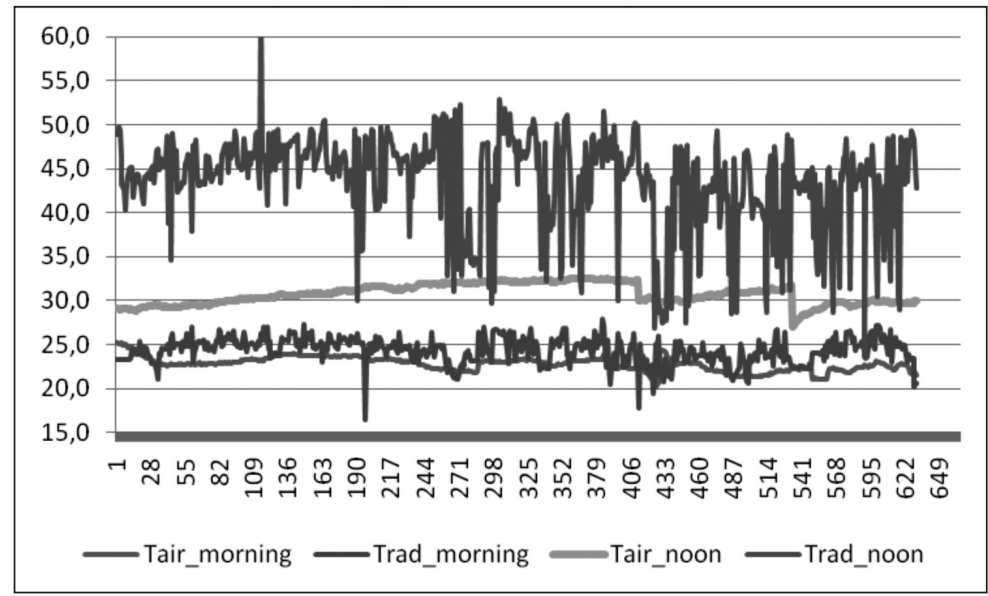

FIgURA 9. Temperaturas del suelo y del aire en diversos puntos de Madrid (26-6-2008) Fuente: Felipe Fernández. Elaboración propia, a partir de los datos obtenidos con instrumentos portátiles situados en vehículos. Proyecto DESIRX.

\section{Impactos de la isla de calor en Madrid y su área metropolitana}

La isla de calor influye directamente en la agudización del estrés térmico en verano y durante los periodos extremadamente cálidos y, de manera indirecta, en el aumento de la mortalidad y del consumo energético.

\subsection{Confort térmico e influencia urbana}

La temperatura del aire, la humedad y el viento son los tres factores que influyen en el confort térmico. En las ciudades, además, juega un importante papel la temperatura emitida por la superficie. Con estas variables hemos obtenido para Madrid y su área metropolitana en índice PET o temperatura fisiológica (Fernández García, 2005) y con ella hemos analizado las transformaciones del bioclima regional, debidas a la urbanización y, también, las diferencias que se observan dentro de la ciudad, como consecuencia de los diferentes usos del suelo y tipologías urbanas. 
La ciudad transforma de manera muy acusada el bioclima regional, disminuyendo las situaciones frías y aumentado de forma notable las cálidas y muy cálidas (Fig. 10).

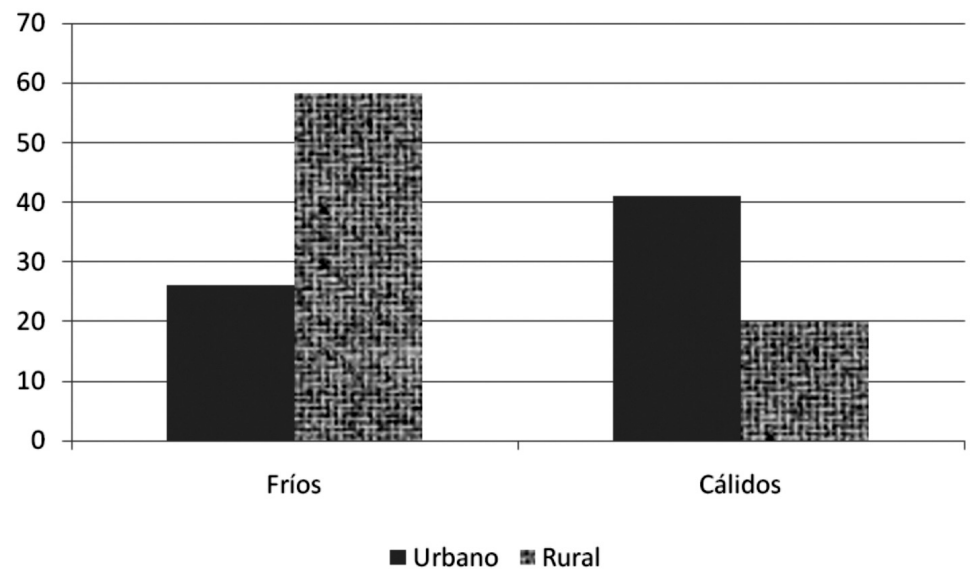

Figura 10. Frecuencia de días fríos y cálidos en la zona urbana de Madrid en el área metropolitana.

Fuente: Felipe Fernández. Elaboración propia con datos la red Urbana de Madrid y al aeropuerto de Barajas. 2000-2004).

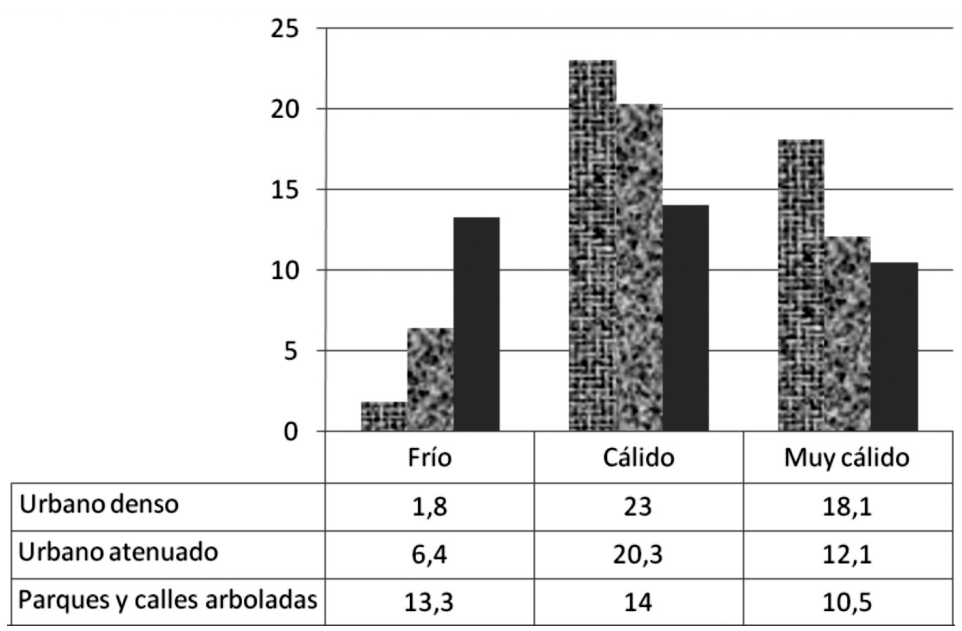

FIgURA 11. Características bioclimáticas y tipologías urbanas en Madrid (Frecuencia de días según las diferentes sensaciones de confort).

Fuente: Felipe Fernández. Elaboración propia con datos de la red meteorológica municipal de Madrid (2000-2004). 
Dentro de la ciudad de Madrid se pueden diferenciar viarios tipos (Fig. 11):

- Tipo urbano: Corresponde a zonas con alta densidad de edificaciones y escasas zonas verdes, los rasgos más significativos de este tipo son: Descenso muy acusado del frío; aumento considerable del calor y ausencia de confort en los tres meses estivales.

- Tipo urbano atenuado: localizado en barrios periféricos de urbanización menos densa y presencia importante de zonas arboladas y césped. Los rasgos característicos son: situaciones de confort similares al anterior, frecuencia de días cálido inferior a la zona urbana y un porcentaje de noches frías más elevado.

- Parques y paseos urbanos arbolados: Este tipo representa las condiciones de confortabilidad de aquellas zonas con abundante presencia de árboles en las que el efecto de sombra se añade a una humedad relativa alta. Las noches frías son más frecuentes que en los tipos anteriores, las noches cálidas son menos frecuentes y disminuyen los días bochornosos.

\subsection{Periodos cálidos y olas de calor}

El calor estival es el rasgo dominante del verano en el área metropolitana madrileña y, durante esa época aumenta la frecuencia de la isla de calor nocturna, que en los meses de junio y julio supera el $90 \%$ de los días y en agosto y septiembre el $88 \%$. (Fig. 12).

El otro rasgo típico del verano madrileño es la alta probabilidad de que aparezcan días extremadamente cálidos, de tal modo que en el periodo 1961-2007, todos los años se ha registrado algún día con temperaturas máximas superiores a $36,5^{\circ} \mathrm{C}$; lo mismo ocurre con las noches cálidas, considerando como tales aquellas en las temperaturas mínimas han sido superiores a $20^{\circ} \mathrm{C}$.

La influencia urbana se manifiesta claramente por el aumento de ambas situaciones, aunque es bastante más acusada durante la noche (Fig. 13).

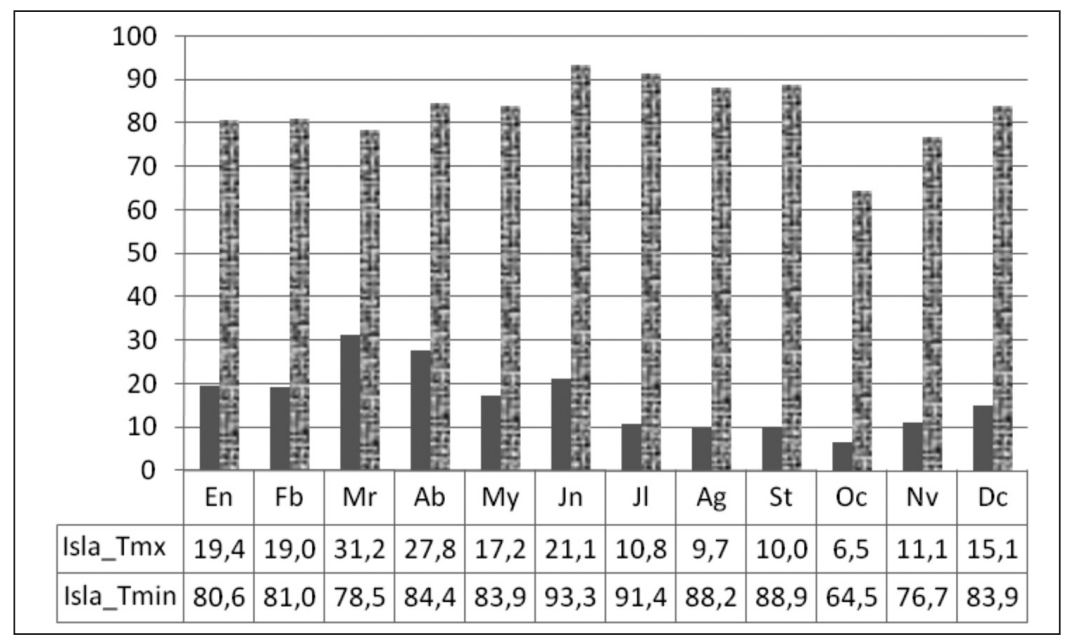

FIgURA 12. Frecuencia de la isla de calor, durante el verano, en Madrid (1961-2000). Fuente: Felipe Fernández. Elaboración propia con datos de la Red Meteorológica Municipal y del observatorio de Barajas. 


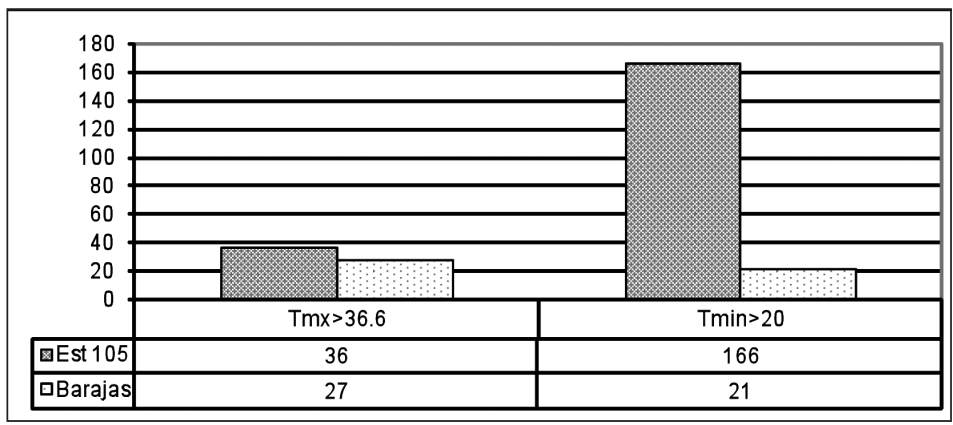

FIGURA 13. Total de días extremadamente cálidos y noches cálidas en el observatorio urbano de la Plaza de Barceló (Est. 105) y en Barajas (2002-2004).

Fuente: Fernández García y Rasilla Álvarez, 2008).

Dentro de la ciudad lo más destacable es la influencia de los espacios verdes que atenúan de forma notable el calor estival, tal y como se puede observar en el mapa de distribución espacial de los días extremadamente cálidos en la ciudad de Madrid (Fig. 14): aparece un claro contraste entre los barrios del sur y suroeste, con un caserío compacto y sin, apenas, espacios verdes, frente a los barrios del norte y nordeste con un caserío más abierto y un porcentaje mayor de zonas verdes. El Parque del Retiro aparece como una auténtica isla de frescor entre espacios bastante más cálidos.

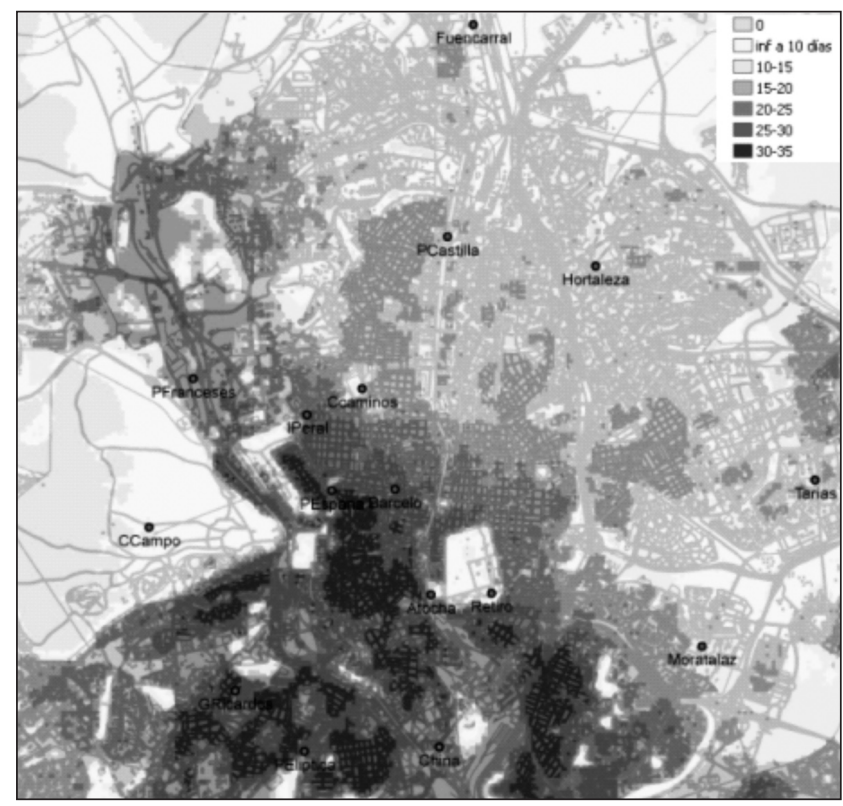

FiguRA 14. Frecuencia anual de los días extremadamente cálidos en Madrid (2002-2004). Fuente: Felipe Fernández. Elaboración propia. 
En el área madrileña, por tanto, la ciudad determina la aparición de tres ambientes bioclimáticos característicos: uno muy cálido, correspondiente a las zonas más densamente urbanizadas; otro cálido, típico de las zonas con escasa influencia urbana y un tercero, relativamente fresco, claramente influenciado por la vegetación, tal y como se observa en el gráfico en el que hemos representado los valores máximos diarios durante la ola de calor de 2003, en Madrid, Barajas y Retiro (Fig. 15). El valor representado corresponde a la Temperatura Fisiológica, que resulta de la combinación de cuatro variables meteorológicas: la humedad relativa del aire, la velocidad del viento, la temperatura del aire y la temperatura radiante, es decir la emitida por las diferentes superficies. En el gráfico, además, aparecen representados los umbrales, por encima de los cuales se pasa de una sensación térmica muy cálida, a la extremadamente cálida. (Fernández García, 2005). El análisis nos muestra como en Madrid ciudad las temperaturas se mantuvieron por encima del umbral extremo, desde primeros de julio, hasta el 24 de agosto cuando la ola de calor comienza a remitir; en Barajas, se mantuvieron durante todo el periodo entre ambos umbrales y, únicamente desde finales de julio al 14 de agosto, coincidieron o superaron el umbral de calor extremo; en el parque del Retiro, nunca alcanzaron las situaciones extremas, manteniéndose la temperatura por debajo del umbral de muy frío. En resumen en los periodos cálidos la ciudad agudiza de forma notable el calor, en relación a las zonas no urbanas y las masas forestales de cierta entidad como el parque del Retiro, actúan de forma muy notable como moderadoras del estrés térmico.

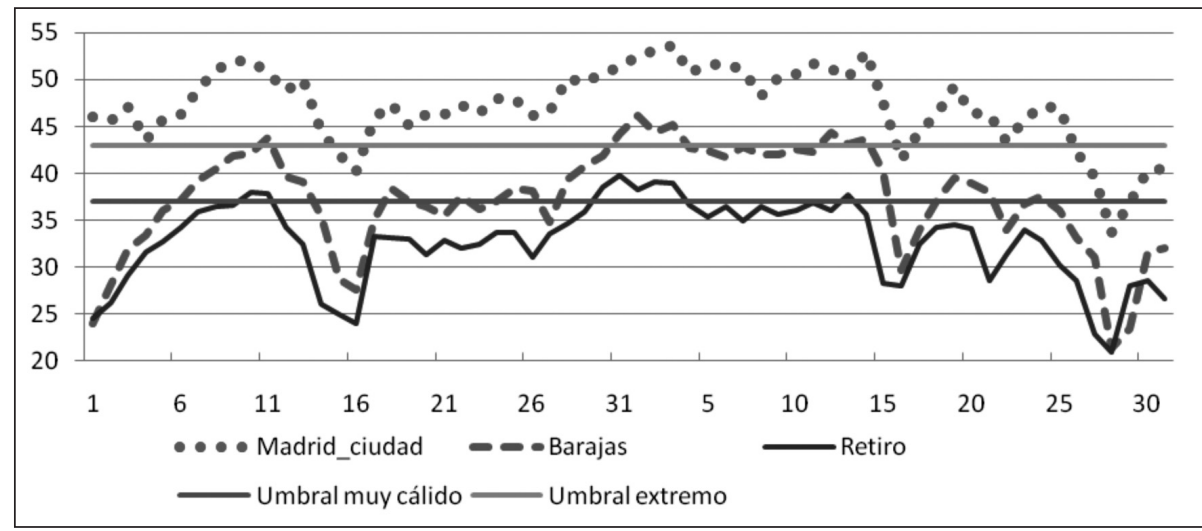

Figura 15. Influencia de la ciudad y los espacios verdes durante la ola de calor de julio y agosto de 2003. Temperatura fisiológica (PET)

Felipe Fernández. Elaboración propia.

\subsection{Impactos de la isla de calor en el consumo energético y la mortalidad}

Aumento de la mortalidad y del consumo de electricidad por el uso de aparatos de aire acondicionado, son las dos consecuencias que se derivan del aumento de la temperatura y que en Madrid se ven agudizados como consecuencia de la isla de calor.

En el verano de 2003 un gran número de regiones europeas sufrió un incremento prolongado de las temperaturas, que provocó un fuerte aumento en la mortalidad. En España se registraron tres períodos de temperaturas elevadas con un exceso de defunciones del $8 \%$, 
lo que representó un incremento de 3166 fallecimientos. En Madrid la mortalidad aumentó un $40 \%$ respecto al verano de 2001 y la distribución por barrios de los fallecidos durante el episodio cálido muestra que el impacto fue mayor en los distritos del sur y suroeste (García y Alberdi, 2003), aquellos en los que la intensidad de la isla de calor es máxima (Fig. 16).
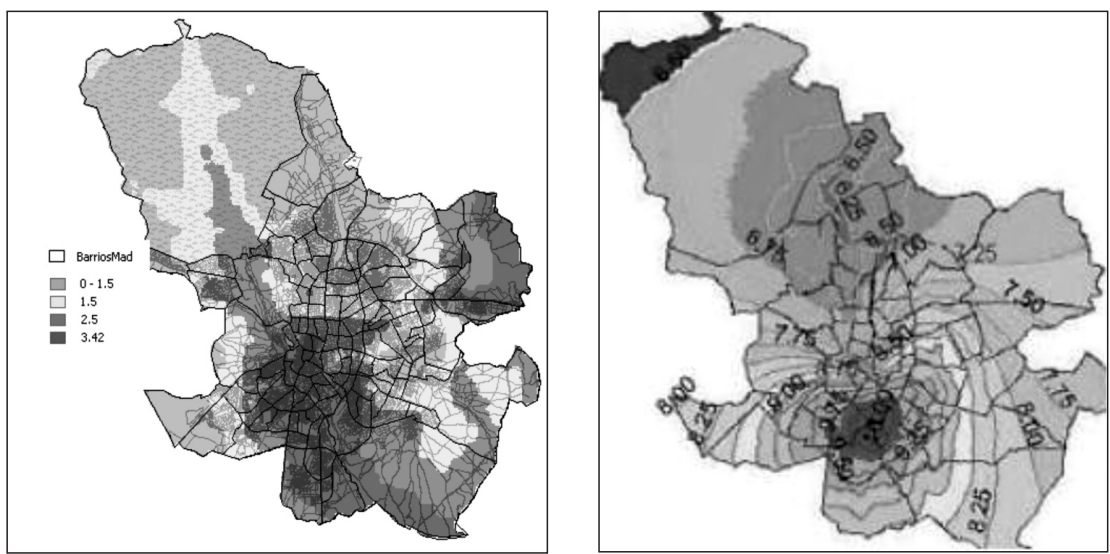

FIGURA 16. Intensidad de la isla de calor (izquierda) y distribución espacial de la mortalidad (derecha), durante la ola de calor de 2003, en Madrid.

Fuente: Felipe Fernández (isla de calor). García y Alberdi (distribución espacial de la mortalidad).

El gasto energético muestra, también, una estrecha relación con la isla de calor, tal y como se muestra en la figura 17 , en la que se representa la relación porcentual de grados día de refrigeración entre los espacios urbanos y la media general del área metropolitana. En las áreas más densamente urbanizadas el gasto se incrementa en un 16\%, mientras que en las zonas de parques y viviendas unifamiliares, desciende hasta un $8 \%$.

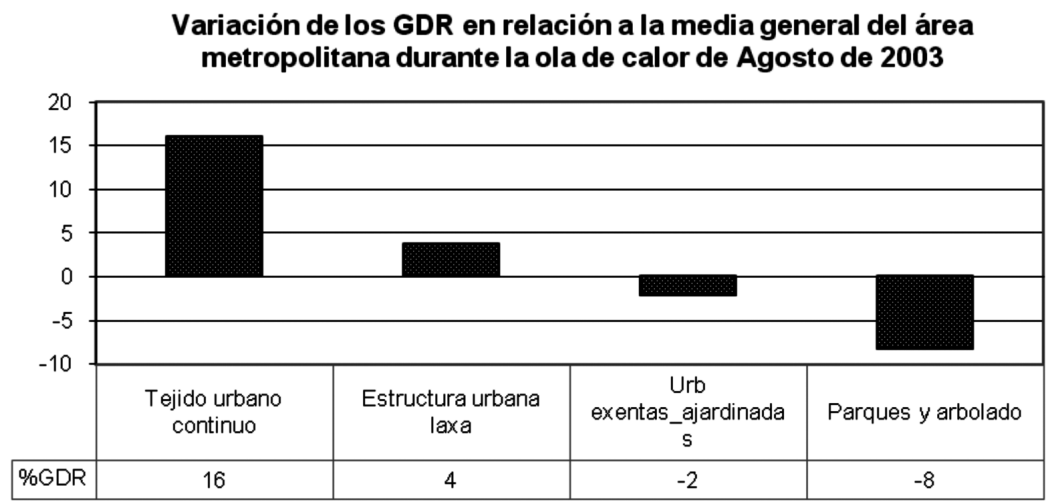

FiguRA 17. Variación del consumo eléctrico para refrigeración y usos del suelo en Madrid, durante la ola de calor de 2003 (\% respecto a la media general del área metropolitana) Fuente: Fernández García y Rasilla Álvarez, 2008. 


\section{Consideraciones finales}

A finales del siglo XIX surgen una serie de estudios en los que se dibuja la ciudad como un lugar insalubre y con un alto riesgo de epidemias y enfermedades, atribuidas a las modificaciones que sobre el medio natural introduce la gran urbe. Hoy, cuando ha pasado más de un siglo desde esta visión, las ciudades continúan siendo áreas contaminadas, inconfortables y ambientalmente insostenibles y el clima urbano es el mejor ejemplo de la acción modificadora del hombre sobre el medio natural, capaz de convertir la ciudad en una isla de calor y su atmósfera en una mezcla de gases contaminantes. Pero hay algo más, lo que en otras épocas aparecía como un fenómeno local, se ha convertido en un fenómeno global y el cambio climático reproduce a gran escala lo que durante tanto tiempo parecía circunscrito a las ciudades.

Estudiar las relaciones entre la ciudad y clima, por tanto, implica analizar dos fenómenos similares, como son el clima urbano y el cambio climático, pero a diferentes escalas; por su parte, los potenciales impactos del cambio climático sobre las ciudades no pueden separarse de los que la propia ciudad ya ha creado en su entorno inmediato:

La isla de calor determina en numerosas ciudades un aumento del estrés térmico y del consumo energético, especialmente en verano. Ambos impactos, relacionados directamente con la presencia de la ciudad, se verán agravados por el aumento de las olas de calor, asociadas al cambio climático.

Otros impactos relacionados con el aumento del nivel del mar, el incremento de huracanes y tornados, afectarán de forma especial a las ciudades costeras.

Tanto en uno como en otros casos, la magnitud e importancia del impacto dependerá de diversos factores como el tamaño de la ciudad, su situación geográfica y sus características socioeconómicas.

Las ciudades, también, contribuyen al cambio climático: de forma directa al ser las principales emisoras de contaminantes a la atmósfera (recordemos que de ellas proceden más del $80 \%$ de las emisiones de GEI); de forma indirecta, debido a las alteraciones ambientales provocadas por el elevado consumo de recursos (más del $75 \%$ del total) y la enorme extensión de la huella ecológica urbana.

En un mundo urbanizado, en el que las previsiones apuntan a que más del $70 \%$ de la población mundial vivirá a mediados del siglo actual en megaciudades, las áreas urbanas constituyen la clave para solucionar el deterioro ambiental ligado al cambio climático. Las estrategias de mitigación a escala urbana incluyen una gama muy amplia de aspectos, entre ellos destacamos las dirigidas a la reducción de la isla de calor y es en este campo, donde la climatología urbana desempeña el papel principal.

Madrid es una zona que reúne todas las condiciones para ser considerada de alto riesgo ante los importantes cambios previstos en el sistema climático; primero, por la gran cantidad de población expuesta a los impactos de las olas de calor, cuya frecuencia será cada vez mayor y, segundo, como consecuencia del crecimiento acelerado y continuo de la urbanización, con la consiguiente expansión de la isla de calor y el aumento de las emisiones de contaminantes. Prevenir a corto plazo estos eventos extremos permitirá amortiguar sus impactos sobre una población cada vez más envejecida, al tiempo que el conocimiento cada más detallado del clima urbano y sus diferentes facetas, será un instrumento para desarrollar políticas urbanísticas que integren en sus planes las condiciones climáticas del entorno. Todo ello favorecerá, a largo plazo, si no crear una ciudad más confortable, al menos evitar un deterioro mayor de su medio ambiente. 


\section{Nota del autor}

Este artículo se ha realizado en el marco del proyecto CGL2009-10057, financiado por el Ministerio de Ciencia e Innovación y del proyecto S2007/HUM-0474, financiado por la Comunidad de Madrid.

\section{Bibliografía}

ALBERDI, J. C., DÍAZ, J., MONTERO, J. C., MIRON, I. (1998): Daily mortality in Madrid community 1986-1992: relationship with meteorological variables. Eur J Epidemiol;14:571-578.

BAUMET, K. and SELMAN, M. (2003): Heating and cooling degree days. Worl Resouces Institute. Disponible en Red http://cait.wri.org

CAM (2006): Vigilancia y control de los efectos de las olas de calor. Plan de respuesta ante los riesgos. Madrid, Instituto de Salud Pública, Servicio de Promoción de la Salud, Documentos técnicos, $30 \mathrm{pp}$.

COPPE, C. et al. (2004): Health and Global Environmental Change. Heat-waves: risks and responses. World Health Organization, $80 \mathrm{pp}$.

DÍAZ, J., GARCÍA-HERRERA, R., TRIGO, R. M., LINARES, C., VALENTE, M. A., HERNÁNDEZ, E. (2006): The impact of summer 2003 heat wave in Iberia: how should we measure it? International Journal of Biometeorology, 50, 159-166.

DÍAZ, J., LINARES, C. y TOBÍAS, A. (2006): Impact of extreme temperatures on daily mortality in Madrid (Spain) among the 45-64 age-group. International Journal of Biometeorology, 50 (6), 342-348.

DÍAZ, J., JORDÁN, A., GARCÍA, R., LÓPEZ, C., ALBERDI, J. C., HERNÁNDEZ, E. and OTERO, A. (2002a): Heat waves in Madrid 1986-97: effects on the health of the elderly. International Archives of Occupational and Environmental Health 75, pp. 163-70.

DESIREX (2008): Campaign . Experiment Plan. Prepared by: José A. Sobrino, University of Valencia (Spain). Date: 7 June 2008.

EBI, K. L. et al. (2004): Heat Watch/Warning Systems Save Lives: Estimated Costs and Benefits for Philadelphia 1995-1998. Bulletin of the American Meteorological Society, 85: 1067-74.

FERNÁNDEZ GARCÍA, F., ALMENDROS COCA, M. A. y LOPEZ GÓMEZ, A. (1994): La influencia del relieve en la Isla de calor de Madrid: las vaguadas del manzanares y el Albroñigal Revista de Estudios Geográficos, n. 224, pp. 473 a 494.

FERNÁNDEZ GARCÍA, F. (2001-2002): El clima urbano de Madrid y su influencia sobre el confort térmico. Boletín de la Real Sociedad Geográfica, CXXXVII-CXXXVIII, pp. 169-185.

FERNÁNDEZ GARCÍA, F. et al. (2003): A PCA analisys of the UHI form of Madrid (Spain). 5th International Conference on Urban Climate, 1-5/9, Lodz, Poland, 2003.

FERNÁNDEZ GARCÍA, F. y MORENO JIMÉNEZ, A. (2004): Confort climático y nivel de renta en la Comunidad de Madrid: un estudio exploratorio de su relación espacial, en Historia, Clima y Paisaje. Estudios geográficos en memoria del profesor Antonio López Gómez, Valencia, Ed. Universitat de Valencia, Universidad Autónoma de Madrid y Universitat de Alicante. pp. 305-321.

FERNÁNDEZ GARCÍA, F. (2005): Contaminación atmosférica y calidad del aire en Madrid: análisis de las concentraciones de $\mathrm{SO}_{2}$, CO, Ozono y PM10 (1980-2003). Revista Estudios Geográficos, LXVI, 259, pp. 507-532.

FERNÁNDEZ GARCÍA, F. (2007): Impactos del cambio climático en las áreas urbanas y rurales. Boletín de la Institución Libre de Enseñanza. 2007, n. 66-67.

GARCÍA HERRERA, R., PRIETO, L., DÍAZ J., HERNÁNDEZ, E. y DEL TESO, T. (2002): Synoptic conditions leading to extremely high temperatures in Madrid. Annales Geophysicae, 20 (2), 237-245.

GARCÍA-HERRERA, R. Et al, (2005): Extreme summer temperatures in Iberia: health impacts and associated synoptic conditions. Annales Geophysicae, 23, 239-251.

KJELLSTRÖM, E., BÄRRING, L., JACOB, D., JONES, R., LENDERINK, G. y SCHÄR, C. (2007): Modelling daily temperature extremes: recent climate and future changes over Europe. Climatic Change, 81, 249-265. 
LÓPEZ GÓMEZ, A. y FERNÁNDEZ GARCÍA, F. (1984): La isla de calor en Madrid: avance de un estudio de clima urbano. Revista de Estudios Geográficos, n. 174, pp. 5 a 34.

LÓPEZ GÓMEZ, A., J., FERNÁNDEZ GARCÍA, F. y MORENO JIMÉNEZ, A. (1993): El clima urbano. Teledetección de la isla de calor en Madrid. Madrid. Ministerio de Obras públicas y Transportes, Serie Monografías. 230 pp.

MIMAM (2005): Evaluación preliminar de los Impactos en España por Efecto del Cambio Climático. Moreno Rodríguez, J.M. (coord.), 822 pp.

MMA (2007): El cambio climático en España. Estado de situación. Informe para el presidente del gobierno elaborado por expertos en cambio climático. Documento resumen, noviembre de 2007. http://www.mma.es/portal/secciones/cambio_climatico/

MMA (2008): Primer informe de seguimiento sobre el desarrollo del Plan Nacional de Adaptación al Cambio Climático. Oficina española del Cambio Climático, 63 pp.

RASILLA ÁLVAREZ, D., y FERNÁNDEZ GARCÍA, F. (2005): Trends on extreme temperature days over the Iberian peninsula. $17^{\text {th }}$ International Congress of Biometeorology. ICB 2005. September 05-09, 2005. Gamisch-Partenkirchen (Germany).

SÁNCHEZ, E., et al. M. (2004): Future climate extreme events in the Mediterranean simulated by a regional climate model: a first approach. Global and Planetary Change, 44 (1-4), pp. 163-180.

TAHA, H. KALSTEIN, L., SHERIDAN, S. y WONG, E. (2005): Impacts of large-scale surface modifications on meteorological conditions and energy use: A 10-region modeling study. Theoretical and Applied Climatology, Vol. 62, pp. 175-185 (1999). 
